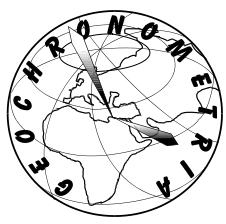

\title{
CHRONOLOGY OF CONSTRUCTION AND OCCUPATIONAL PHASES OF NAWAMIS TOMBS, SINAI BASED ON OSL DATING
}

\author{
IOANNIS LIRITZIS ${ }^{1}$, NIKOLAOS ZACHARIAS ${ }^{2}$, FAHAD AL-OTAIBI ${ }^{3}$, IOANNIS ILIOPOULOS ${ }^{4}$, \\ CHRISTOS KATAGAS ${ }^{4}$ and MOSSALAM SHALTOUT ${ }^{5}$ \\ ${ }^{I}$ King Saud University, Riyadh, Saudi Arabia \& Lab of Archaeometry, Dept of Mediterranean Studies, \\ University of the Aegean, Rhodes, Greece \\ ${ }^{2}$ Laboratory of Archaeometry, Department of History, Archaeology and Cultural Resources Management, \\ University of the Peloponnese, 24133 Kalamata, Greece \\ ${ }^{3}$ King Saud University, Dept of History, Riyadh, Saudi Arabia \\ ${ }^{4}$ Department of Geology, University of Patras, 26504 Rio, Greece \\ ${ }^{5}$ National Research Institute of Astronomy and Geophysics (NRIAG), Helwan, Cairo, Egypt
}

Received 8 March 2016

Accepted 19 September 2016

\begin{abstract}
The Nawamis are sandstone-built circular structures, located at several sites across Southern Sinai, Egypt. They are thought to be family tombs, created by the nomadic people that inhabited the area. Archaeological age estimates fall within the Early to Late Bronze Age. Here an interesting suite of nine OSL dates of three stone pieces has been resulted, from two Nawamis at Gebel Gunna and Ain Khodra fields. Single aliquot regeneration OSL of quartz grains provided the accumulated dose. XRD was used to identify mineralogy of several tombs. Based on the estimated luminescence ages a time span from Early and late Bronze ages is obtained, while some possible later activity, due to partial (re)construction or reuse of tombs, was detected.
\end{abstract}

Keywords: Nawamis, surface luminescence dating, Bronze Age Levant, SAR-OSL, XRD.

\section{INTRODUCTION}

The Nawamis are stone-built circular structures, located at several sites across Southern Sinai (Fig. 1).

Earlier rescue excavations at Gebel Gunna have reported skeletons, lithic axes, scrappers, some copper bronze, grinding stones, hammer stones, beads, shells, with much debitage and debris.

According to initial excavators (Bar-Yosef et al., 1977, 1986) Nawamis appear to be family tombs, made by nomads, that inhabited the area. The age inferred by ceramic and artifact typology, as well as, C14 of charcoal

Corresponding author: I. Liritsiz e-mail: liritzis@Rhodes.Aegean.gr assigns them to a range of Early Bronze Age (EB) I, II mainly EB II. ( $c a .2700$ B.C.), though Late Bronze age (1550-1200 BC) artifacts are also reported. Reuse of tombs evidenced from diagnosed finds has been noticed with later Roman-Byzantine period, even with some Bedouin burials of unknown age- all of which though may have been subjected to unnoticeable repairs. Primary and secondary burials were mixed and disturbed in historic times (Bar-Yosef et al., 1977, 1986).

There are approximately 1000 Nawamis in Sinai, some of them in very good condition, others almost destroyed (Hershkovitz et al., 1985; Bar-Yosef et al., 1983).

All Nawamis are characterized by the same have same rounded plan, 3 to 6 meters in diameter and about 2 meters height. They are double-walled structures, built on local rocks, usually sandstones. The outer wall is standing upright and the inner wall rises in an arch and forms a 


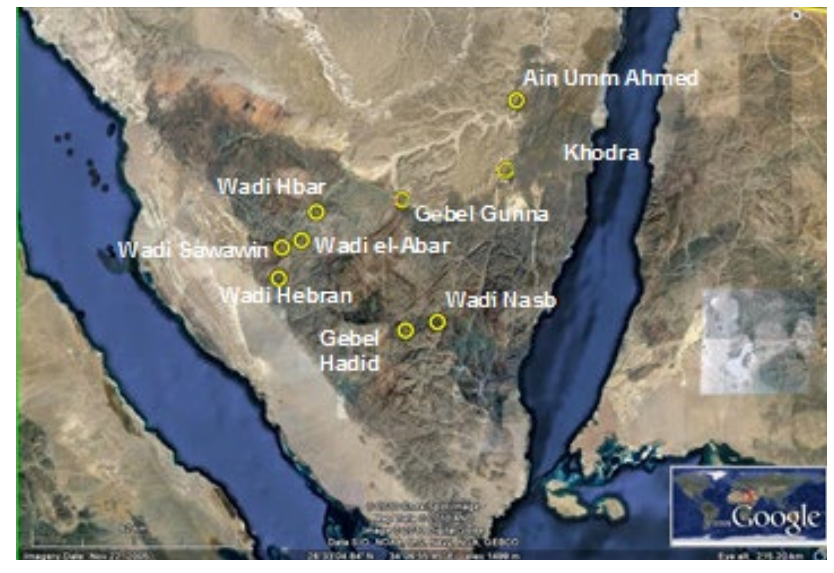

Fig. 1. Location of Nawamis in the Sinai Peninsula for the sites of Gebel Gunna and Ain Khodra.

corbelled roof lidded by a larger slab. They were built by rough rectangular slabs fit one to another and in a simple manner of construction. The entrances are small corridors made by one or two standing slabs, that remained in place despite later collapse of some of them. In the preserved ones their entrances appear to face west.

Optically stimulated luminescence dating (OSL) followed surface luminescence dating procedures of Litizis et al. (2013a) to date for first time two Nawamis, in Gebel Gunna and Ain Khodra areas, to investigate construction or re-use of these nomadic tombs.

The geolithology of the area comprises of sandstones intercalating with various carbonate rocks and shales, which belong to the Mahla Formation (Wanas, 2011). These are unconformably underlain by low-lying sandstone of the Naqus formation, which together with the granitic rocks of the Precambrian basement form a pronounced relief reaching about 1200 meters above sea level.

\section{LUMINESCENCE DATING OF WALLS: THE RATIONALE}

The luminescence technique employed in this study has been introduced during the 90's (Liritzis, 1994), and thereafter tested and published elsewhere (Huntley and Richards, 1997; Habermann et al., 2000; Morgenstein et al., 2003; Greilich et al., 2005), with an overview of the surface dating reported later in this journal by Liritzis (2011), followed by successfully applied case studies (Sohbati, 2013; Liritzis et al., 2013a, 2013b, 2015; Liritzis and Vafiadou, 2014) or reported in review articles about the use of OSL in different materials (Roberts et $a l ., 2015)$. In masonry it involves dating the inter-block surfaces of building stones which relies on the optically sensitive electron traps responsible for OSL light in the surface layer of the carved rock, having been bleached by sunlight, prior to the blocks being incorporated into the structure. The sunlight bleaching of quartz in sandstone surfaces is in fact fast (Liritzis et al., 2010b; Liritzis and Vafiadou, 2014). Subsequently, the slabs exposed to sunlight are moved in the appropriate position of the structure and overlaid by another block. From the moment that any surface is no longer exposed to sunlight and put in firm contact (with or without mortar), the optically sensitive electron traps are filled by electrons produced by the ionization caused from nuclear radiation of natural uranium, thorium, potassium, rubidium and cosmic radiation. These isotopes are present in the rock slabs and the soil surrounding the sampling point. Thus, the age can be given by Eq. 2.1:

Age $=\mathrm{ED}(\mathrm{Gy}) / \mathrm{DR}(\mathrm{mGy} / \mathrm{yr})$

The equivalent dose (ED, in Grays, Gy) is measured by (OSL) following standard procedures of SAR (Murray and Wintle 2000; Greilich et al., 2005; Liritzis et al., 2010b).

The annual dose rate (DR, in mGrays per year) denotes the radiation dose accumulated in a year. It is comprised of the three-radiation dose components (alpha, beta and gamma radiation) derived from the natural radioisotopes of uranium (U-238), thorium (Th-232), potassium (K-40), and rubidium (Rb-87), of the sample itself and the surrounding environment, and includes cosmic-rays (Aitken, 1985).

\section{SAMPLING}

With the aid of a chisel and a hammer samples were detached from firm contacts and swiftly covered to avoid sun exposure. In fact care was taken when removing the samples to avoid light: sampling was made during the sunset working under an in situ mini tent to light deprive, they were gently chipped and when loose while still in original position in the wall and covered by mortar, were gently removed being wrapped by black plastic bags, while adherent sand on the contact of the two cobbles was collected too (Liritzis et al., 2010, 2015; Liritsiz 2010). Surficial pieces of rock about $6-8 \mathrm{~cm}^{2}$ and at least $0.5 \mathrm{~cm}$ thick were detached. (Fig. 2). By adhering to this protocol, we insure that the samples collected in the field were not exposed to light.

At Gebel Gunna 6 inside the rectangular structure wall sampling was made about $60 \mathrm{~cm}$ above the bedrock floor, and from Ain Khodra 8 both samples came from the external wall at a height of about $1.00 \mathrm{~m}$ above bedrock ground (Fig. 3). Nine sub-samples were processed from three removed pieces; one piece derived from Gebel Gunna tomb (the GG6 with three sub-samples), and two pieces from Ain Khodra (AK8.1, with two sab-samples, and AK8.2 with four sub-samples from both surface faces).

A surface layer of about $50 \mu \mathrm{m}$ (measured by a micrometer), which included organic material, dust, and adherent contamination, was removed from the inner surface by briefly inserting it in dilute hydrochloric acid 


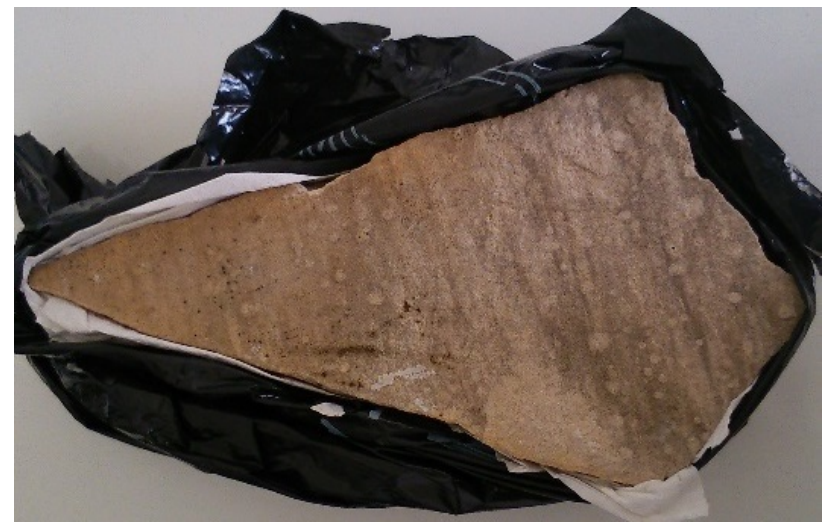

Fig. 2. Actual sample obtained from the structures, wrapped in opaque bag to avoid sunlight. (scale: longer length $\sim 4 \mathrm{~cm}$ ). Here the opposite side is shown that is of no interest to dating for clarity of sample size and shape.

$\mathrm{HCl}$ acid (10 wt $\%)$ and rinsed with running water. Subsequently, a thin layer of surface polymineral powder was acquired by gently scraping the inter block surface to a depth of less than $0.5 \mathrm{~mm}$ (making a series of readings with a micrometer) and transferred to an acetone bath where grains were collected, washed in dilute acetic acid (5 $\mathrm{wt} \%$ ) for $1 \mathrm{~min}$, and dried. Medium sized grains of sandstone were sieved to a diameter of $50-110 \mu \mathrm{m}$, washed in HF for 45 min to remove a layer of $\sim 25 \mu \mathrm{m}$ to avoid alpha particle dose rate contribution, prior to OSL measurements.

Sub-samples of the ancient carved surface were taken (by dividing the surface into sizeable parts to acquire sufficient quantity powder for SAR and tests), to reassure regions of interest (ROI) that were not subjected to possible effect of friction (from past earthquake) of two stones in contact. Such an event destroys originally bleached surface layer and provides powder of deeper surface layers not bleached and thus inhere geological luminescence. Where appropriate, two or three sub ROI were selected (see Fig. 6) (in fact, two contact surfaces do not touch each other completely, but there exist sub-areas at the millimeter level of voids; those sub-areas of interest are searched for obtaining consistent equivalent doses, with others, usually high values, as outliers, discarded regarded of geological origin).

\section{INSTRUMENTATION \& MEASUREMENTS}

Prior to any sample preparation the mineralogy was checked by $\mathrm{XRD}$, then equivalent dose and dose rates were measured. XRD analyses were performed on the same samples (Ain Khodra 8, Gebel Gunna 6) that were used for dating, as well as, from other rock types of local environment shown in Table 1 . Stone was visually similar but mineralogical characterization was decided to be a necessity in order to detect differentiations that potentially point to the exploitations of different quarries and/or different chronological periods of use; checking even small variations was of interest and as a future reference too.

\section{XRD analysis}

A small aliquot from the samples was used in order to determine the mineralogical composition by means of $\mathrm{X}$ ray powder diffraction (XRD) analysis. Samples were firstly dried in a laboratory oven at $110^{\circ} \mathrm{C}$ for $24 \mathrm{~h}$ and then grinded in a vibration disc mill using an agate grinding set. The samples were then analysed in a Bruker D8 Advance X-Ray diffractometer, with Ni filtered $\mathrm{CuK} \alpha$ radiation, operating at $40 \mathrm{kV} / 40 \mathrm{~mA}$, in the Laboratory of Mineral and Rock Research of the Department of Geology at the University of Patras, Greece. The scanning area covered the interval $2^{\circ}-70^{\circ} 2 \theta$, with a scanning angle step of $0.015^{\circ} 2 \theta$ and a time step of $0.1 \mathrm{~s}$ (Iliopoulos et al., 2011). The interpretation of the acquired diffractograms and mineral identification was performed using DIFFRACplus EVA software (Bruker-AXS, Madison, WI, USA) based on the International Centre for Diffraction Data Powder Diffraction File (2006). Representative rocks from several tombs are examined. The rock was identified as sandstone with predominant quartz, few kaolinite and only traces of other minerals such as calcite, hematite, gypsum and muscovite (Table 1 and Fig. 4). Lazurite was only identified in the sample from Gebel Gunna 2 (Airp2). This blue colored mineral is the essential ingredient of lapis lazuli, a precious stone well known in prehistoric times, which was widely imported from Afganistan to Egypt. The composite XRD diagram of Fig. 4 illustrates well the quartz predominance in all samples.

Table 1. Mineralogical composition of the analyzed samples as determined through XRD analysis. Airp stands for rocks around airport (+: dominant; $x$ : present; tr: traces; -: not determined).

\begin{tabular}{|c|c|c|c|c|c|c|c|}
\hline Sample ID & $\frac{\underset{T}{T}}{\sigma}$ & 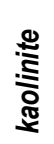 & $\frac{\stackrel{D}{J ~}}{\mathbb{J}}$ & 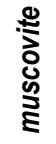 & $\begin{array}{l}\stackrel{\mathbb{J}}{\mathbb{\Xi}} \\
\stackrel{\Xi}{\Xi}\end{array}$ & 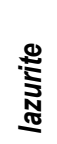 & 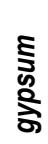 \\
\hline Airp 1 & + & $x$ & $\mathrm{x}$ & - & - & - & $\operatorname{tr}$ \\
\hline Airp 2 & + & $\mathrm{x}$ & $\operatorname{tr}$ & $\operatorname{tr}$ & - & $\operatorname{tr}$ & - \\
\hline Airp 3 & + & $\mathrm{x}$ & $\mathrm{x}$ & - & - & - & - \\
\hline Airp 5 & + & $\mathrm{x}$ & $\operatorname{tr}$ & - & - & - & - \\
\hline Airp 7 & + & $\mathrm{x}$ & - & - & $x$ & - & - \\
\hline Airp 14 & + & $\mathrm{x}$ & $\mathrm{x}$ & - & - & - & tr \\
\hline Airp 6 (Ain Khodra 8.1) & + & $x$ & $\operatorname{tr}$ & - & - & - & - \\
\hline Gebel Gunna 6 & + & $\mathrm{x}$ & - & $\operatorname{tr}$ & $\operatorname{tr}$ & - & - \\
\hline
\end{tabular}




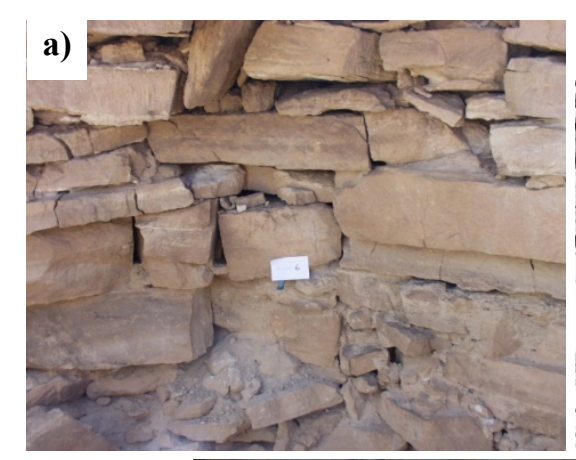

d)
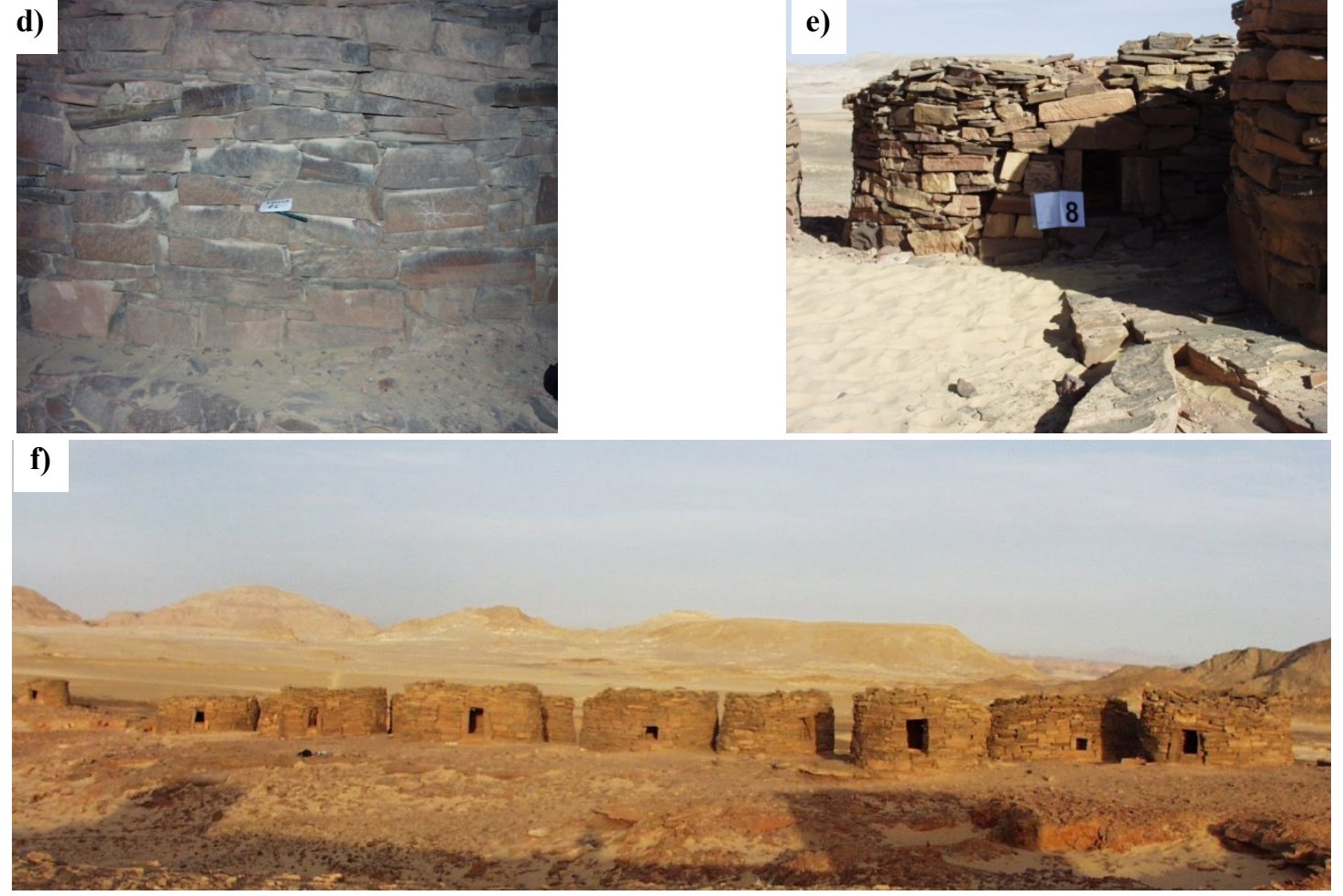

Fig. 3. a) Gebel Gunna No 6. The sampling point (scale of white paper length $20 \mathrm{~cm}$ ) where piece of slab was taken from inside the tomb, by a hammer and chisel b) another view of the inside with the slabs and rough construction, and c) a view of the back that indicates the construction manner. Height of tombs $\sim 2$ meters and wall width $\sim 1 \mathrm{~m}$ (The A4 white paper sheet acts as a scale on the external wall) d) Ain Khodra no 8 sampling from back side, and e) the entrance face (scale as A4 paper and in sampling point paper length is $20 \mathrm{~cm}$ ) f) also a cluster of tombs around the sampled one.

\section{Dose Rate}

$\mathrm{U}$ and Th were measured from alphas with the pairs technique by a calibrated alpha counting system; a 7286 Low Level Alpha Counter, Littlemore Sci. Eng Co Oxford with a PM tube type EMI 6097B using $\mathrm{ZnS}(\mathrm{Ag})$ films. Alpha counts converted to concentrations and were calibrated on reference standards following devised conversion factors as well as relevant computations (Aitken, 1985; Liritzis and Vafiadou, 2012). Potassium (K\%) content was measured by Flame Atomic Absorption Spectroscopy (FAAS) and a minor contribution by $\mathrm{Rb}$ to inclusion from the ratio Kppm/Rbppm equal 200/1. (Aitken, 1990; Warren, 1978). FAAS was made by Perkin Elmer, USA mod.: Analyst 800 Dual System (Flame and Graphite Furnace ionization). The standard procedure was applied i.e. $0.2 \mathrm{~g}$ of sample was transferred to solution in a microwave oven in the presence of $5 \mathrm{ml} \mathrm{HF}$ (49\%) and $5 \mathrm{ml} \mathrm{HNO3} \mathrm{(69.5 \% ).} \mathrm{Thereafter} \mathrm{it} \mathrm{was} \mathrm{diluted}$ to $100 \mathrm{ml}$. The calibration standard used was SARM 69, from which five solutions of different concentration made the calibration curve. For the conversion from content to dose rate the recent updated factors are used (Liritzis et al., 2013c). 


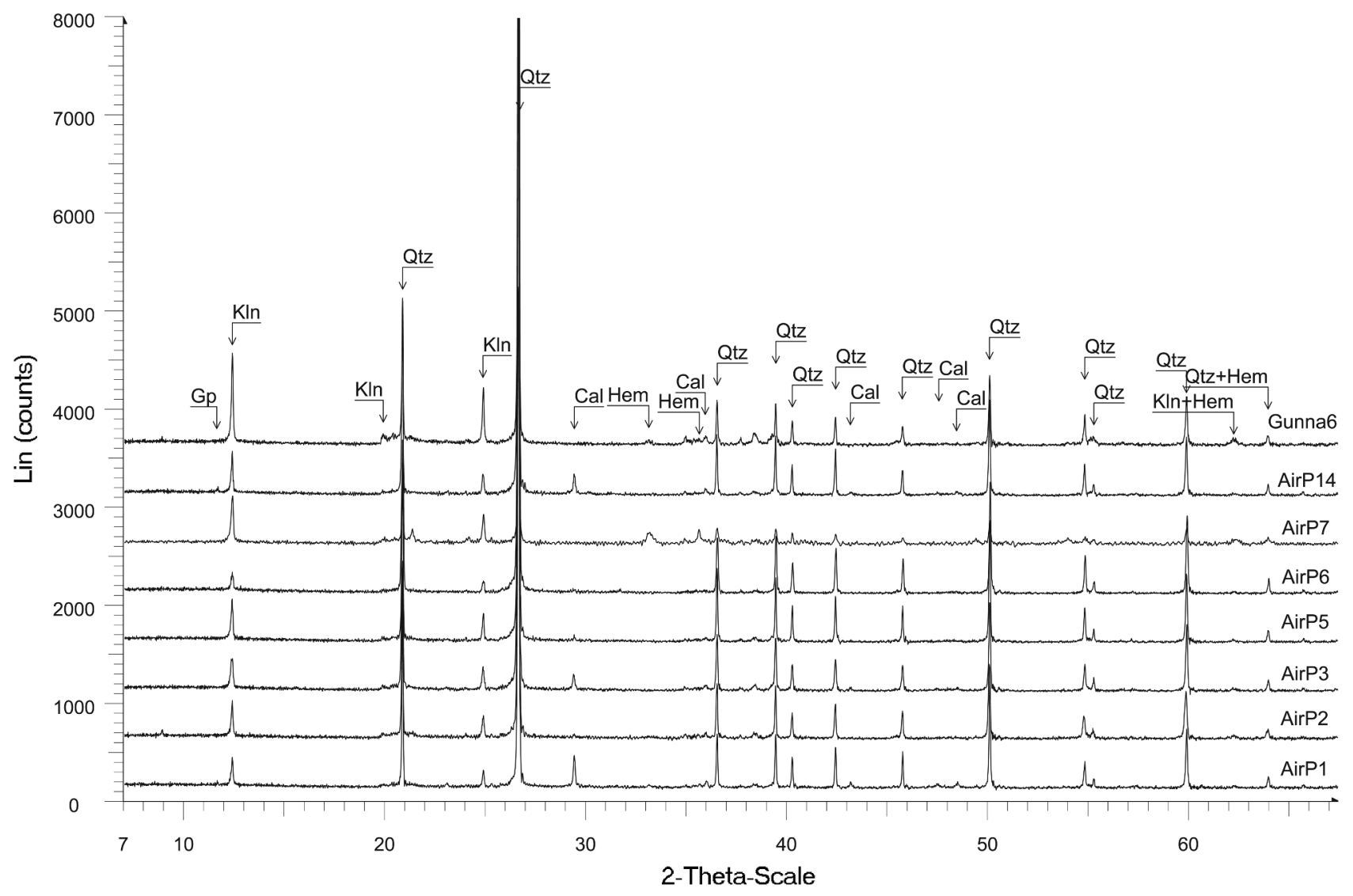

Fig. 4. Composite diagram including the X-ray diffraction patterns of all the samples analysed. Mineral abbreviations are according to Kretz (1983) (main mineral phases Qtz: quartz, KIn: kaolinite, Cal: calcite; Hem: hematite).

The dose rate consists of the sum of beta and gamma dose rates as the outer layer of quartz grains affected by alpha irradiation was removed by acid treatment. However, the sampling position has not a straightforward dosimetry geometry (e.g. sandwiched been sediment layers or sample surrounded by an homogeneous medium in the center of a sphere of radius $\sim 35 \mathrm{~cm}$ ), therefore, dose rates were case sensitive and individually estimated (piece detached from a wall, above a sandy floor etc.). Details are given as follows: Rubidium values are calculated based on $\mathrm{K} / \mathrm{Rb}=200$. The total beta particle doses-rates are halved (lower stone surface plus upper mortar) and include an attenuation factor of 0.90. For GG6.1 the total D $\gamma$ is $1.19 \mathrm{mGy} / \mathrm{yr}$. The Dy from sand is $1.55 \mathrm{mGy} / \mathrm{yr}$ and from stones $0.36 \mathrm{mGy} / \mathrm{yr}$. The sampling point is $60 \mathrm{~cm}$ above floor and if considered as a center of a sphere of radius $\sim 30 \mathrm{~cm}$ (for solid medium, but some meters through air medium) which receives gamma rays dose within $30 \mathrm{~cm}$, including the rock itself, adjoining rocks and mortar, and air from the opposite face of the block: In particular, half gamma dose-rate (equal of $0.180 \mathrm{mGy} / \mathrm{yr}$ ) from the rear $1 \mathrm{~m}$ thick wall and from skyshine inside the enclosed structure of similar stones and the floor, an approximate $25 \%\left(1 / 4^{\text {th }}\right.$ of the spherical representation of mixed media around the sampling point) from ground floor sand of $0.39 \mathrm{mGy} / \mathrm{yr}$, plus, $25 \%$ from ceiling $0.09 \mathrm{mGy} / \mathrm{y}$. The latter two were estimated from the fact that $70 \%$ of infinite gamma dose medium (from K-40, U238, Th-232) is recorded on surface, and about $25 \%$ at a height of 1 meter above ground (Beck and Planque, 1968; Thompson et al., 1999; Liritzis and Galloway, 1981). For AK8.1.1 the half D $\gamma$ dose-rate is used as sample derives from external wall, total Dy is $1.17 \mathrm{mGy} / \mathrm{yr}$. Water uptake measured to be zero. Cosmic rays dose rate for latitude $28^{\circ} \mathrm{N}$ and longitude $34^{\circ} \mathrm{E}$ and altitudes $850-1300 \mathrm{~m}$ a.s.l. at Sinai is estimated as $0.30 \mathrm{mGy} / \mathrm{yr}$. The penetration through some centimeters in slabs is estimated to be reduced to $0.25 \mathrm{mGy} / \mathrm{yr}$ (Prescott and Hutton, 1994). Total dose rate includes cosmic $0.25 \mathrm{mGy} / \mathrm{yr}$ and $0.1 \mathrm{mGy} / \mathrm{yr}$ internal radioactivity in quartz.

$D_{\beta}$ were contributed to the surface by half from the lower stone where sample powder originates plus half from upper $2 \mathrm{~mm}$ layer of sand; from the upper stone surface betas do not reach the lower surface since attenuated by space and introduced sand, while about $20 \mathrm{mi}-$ 
crons are removed during cleansing of surface that precludes alpha particles dose.

\section{Equivalent Dose-SAR technique and Resulted Dates}

All OSL measurements were conducted in the continuous wave OSL mode of an OSL reader (model Risø $\mathrm{TL} / \mathrm{OSL}-\mathrm{DA} 15$ ) at $125^{\circ} \mathrm{C}$ for $100 \mathrm{~s}$. Stimulations were made under blue LEDs light source $(\lambda \mathrm{p} \sim 470 \mathrm{~nm}$, FWHM $30 \mathrm{~nm}$ ) and irradiations with a calibrated 0.075 $\mathrm{Gy} / \mathrm{s}{ }^{90} \mathrm{Sr}{ }^{90} \mathrm{Y} \beta$-ray source (Bøtter-Jensen et al., 2000).

Heating was carried out using a heating rate of $1{ }^{\circ} \mathrm{C}$, in order to avoid thermal gradient and $7.5 \mathrm{~mm}$ Hoya U-340 $(\lambda \mathrm{p} \sim 340 \mathrm{~nm}, \mathrm{FWHM} 80 \mathrm{~nm})$ filter for the detection optics. The power level was software controlled and set at $90 \%$ of the maximum power of the blue - LED array, delivering at the sample position $\sim 32 \mathrm{~mW} \mathrm{~cm}{ }^{-2}$. The background OSL levels measured after 95-100 seconds exposure were subtracted from the initial luminescence intensity ( $0-1$ seconds) of the decay curves obtained. The De was determined on recovered traces of quartz from sandstones (Liritzis et al., 2010b, 2015, Liritzis and Vafiadou, 2014). OSL signals present an extremely rapid decay in the first seconds of stimulation, providing thus a strong indication regarding the presence of a unique fast component, being dominant at the initial part of the OSL curves. The numbers of aliquots/per sample were very restricted due the nature and the availability of the samples and ranged from 2 to 5; only sample AK8.2.4 provided powder for 7 aliquots (cf. notes on Table 2).
Quartz grain aliquots which were collected in earlier steps during sample preparation (and suspected as being partially or totally bleached) for both samples following SAR, was used to perform initial tests like signal growth, preheat and dose recovery tests and those were 2 aliquots made from sample GG.6.1 and 3 samples made from AK.8.2.4.

Below an OSL shine-down curve is given for an aliquot from sample AK.8.2.4 that was used as a test sample (Fig. 5).

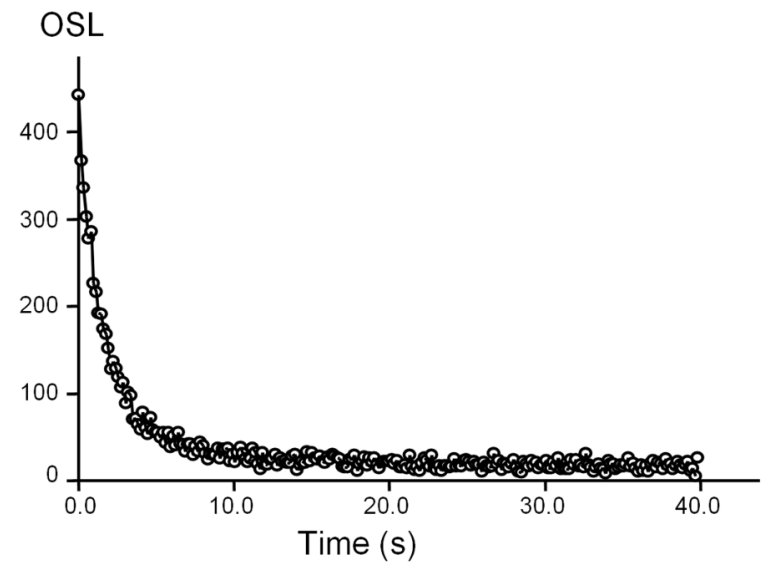

Fig. 5. OSL shine-down curve from sample AK.8.2.4.

Table 2. Luminescence measurements data. (GB: Gebel Gunna, AK: Ain Khodra).

\begin{tabular}{|c|c|c|c|c|c|c|c|c|c|}
\hline Sample No & $\underset{(\mathrm{ppm})}{\mathrm{U}}$ & $\begin{array}{c}\text { Th } \\
\text { (Ppm) }\end{array}$ & $\begin{array}{c}K \\
(\%)\end{array}$ & $\begin{array}{c}\mathrm{Rb} \\
(\mathrm{Ppm})\end{array}$ & $D \beta$ & Dy & $\begin{array}{l}\text { ED1 } \\
\text { (Gy) }\end{array}$ & $\begin{array}{c}\text { Age } \\
\text { (yrs BC) }\end{array}$ & $\begin{array}{c}\text { Annual } \\
\text { Dose, } \\
(\mathrm{mG} / \mathrm{yr})^{2}\end{array}$ \\
\hline$\overline{\mathrm{GG} 6.1}$ & $0.55 \pm 0.077$ & $4.97 \pm 0.32$ & $0.21 \pm 0.008$ & 10.5 & $0.85 \pm 0.1^{3}$ & $0.43 \pm 0.04^{4}$ & $4.83 \pm 0.33(3)$ & $1800 \pm 320$ & 1.28 \\
\hline GG6.2 & $\gg$ & $\gg$ & $\gg$ & $\gg$ & $\gg$ & > & $5.60 \pm 0.45(5)$ & $2370 \pm 300$ & $\gg$ \\
\hline GG6.3 & $\gg$ & $\gg$ & $\gg$ & $\gg$ & $\gg$ & $\gg$ & $5.75 \pm 0.75(3)$ & $2490 \pm 450$ & $\gg$ \\
\hline Average & & & & & & & & $2220 \pm 300$ & \\
\hline Sand (floor) & $4.0 \pm 0.09$ & $13.8 \pm 1.0$ & $2.50 \pm 0.1$ & 123 & & & & & \\
\hline AK8.1.15 & $0.89 \pm 0.07$ & $2.98 \pm 0.23$ & $0.1175 \pm 0.005$ & 6 & $0.20 \pm 0.0076$ & $0.85 \pm 0.04$ & $4.89 \pm 0.23(2)$ & $2660 \pm 230$ & 1.05 \\
\hline AK8.1.2 & $>$ & $>$ & $\gg$ & $\gg$ & $>$ & $\gg$ & $4.69 \pm 0.35(2)$ & $2470 \pm 300$ & $>$ \\
\hline Average & & & & & & & & $2560 \pm 250$ & \\
\hline AK8.2.1 & & & & & & & $3.68 \pm 0.35(3)$ & $1500 \pm 350$ & $\gg$ \\
\hline AK8.2.2 & & & & & & & $3.48 \pm 0.23(3)$ & $1310 \pm 230$ & $\gg$ \\
\hline Average & & & & & & & & $1400 \pm 280^{7}$ & \\
\hline AK8.2.3 & & & & & & & $4.34 \pm 0.40(5)$ & $2130 \pm 370$ & $\gg$ \\
\hline AK8.2.4 & & & & & & & $3.13 \pm 0.25(7)$ & $980 \pm 240$ & $\gg$ \\
\hline
\end{tabular}

${ }^{1}$ Numbers in brackets in this column indicate number of aliquots measured. The attached errors in all rows were calculated in $1 \sigma$ probability; for the errors standard errors given in the ED values, these represent the standard errors of the mean value (e.g. 0.33 for 3 aliquots in samples GG6.1).

2Errors $7-12 \%$.

${ }^{3}$ Half from lower plus half upper $2 \mathrm{~mm}$ layer of sand of $0.58 \mathrm{mGy} / \mathrm{yr}$. Includes internal quartz dose.

${ }^{4}$ For GG6.1 final Dy see text, includes cosmic rays dose rate.

${ }^{5}$ For AK8.1.1 sample derives from external wall. 6 .

${ }^{6}$ Thickness of sandy powder $3 \mathrm{~mm}$ of $0.08 \mathrm{mGy} / \mathrm{yr}$, betas include internal quartz dose.

${ }^{7}$ AK8.2 derives from adjacent slab of AK8.1; Upper slab's surface is AK8.2.1 and 8.2.2; Lower slab's surface is AK8.2.3 and AK8.2.4, not averaged due to large difference. 
However, in the sole monolayer aliquots composed by quartz grains resetting of luminescence signal due to solar exposure has been documented, but it is not expected for quartz grains in composite stones likewise sandstones and calcareous schists. Longer sun exposures ensure complete bleaching, in concordance to earlier literature accounts and theoretical considerations of photon attenuation in rocks with depth (Liritzis and Bakopoulos, 1997, Liritzis and Galloway, 1999; Habermann et al., 2000; Greilich, 2004; Greilich et al., 2005; Vafiadou et al., 2007; Laskaris and Liritzis, 2011).

Nine sub-samples were processed derived from three removed stone pieces, two from Ain Khodra and one from Gebel Gunna (Table 2). The flat limited surfaces of the detached pieces which were wrapped in blue opaque bags were divided into regions of interest (ROI) (Fig. 6) where from separate EDs were measured. The latter precaution avoids possible friction which may remove sub areas of the original sun exposed surface. Surface sample was prepared as described above in section 2. All aliquots were checked with infrared (IR) stimulation to ensure the absence of feldspars. The dose recovery test (Fig. 7) varied $\pm 15 \%$ around unity and the recycling point around $12 \%$ (the dispersed one in GG6.2 given the errors is reasonable; large scatter in the measurement could be due to random error during readouts). A pre-heat test (Fig. 8) provided the $220^{\circ} \mathrm{C}$ as the suitable to the material temperature threshold.

\section{DISCUSSION}

The burial structure at Gebel Gunna was amongst a set of six cists built of standing slabs and irregular cobbles, the ground level was sand and skeleton, ribs, other bones and beads were found that date to Late Bronze Age (Bar-Yosef et al., 1983, 1986). According to archaeologists its relationship to the neighboring structures at Gunna area is unclear. Typological examination and radiocarbon dating indicated $3^{\text {rd }}$ millennium BC: for example, the two C-14 ages, at Gunna 25 of $4025 \pm 72$ BP (SMU-659) and at Gunna 100 of $4373 \pm 64$ BP (SMU-659) on charcoal from ovens, dug down to bedrock, located in same tomb, cluster but outside the age group of circular tombs (Bar-Yosef et al., 1986). It is worth mentioning the found skeleton of Roman-Byzantine period too. While tombs were used as primary burials, re-use of the structures has been noticed. They were mixed with secondary (later) burials, and/or later historical interventions. This is not surprising because strong stone structures are akin to be reused by later generations. Luminescence dating addresses this as it reinforces an additional value of being applied to reconfirm or question the age of internal findings and its intimate or far relationship with initial construction date.

The estimated ages vary between 1000-2400 BC for the two structures studied, obviously their cluster per sampling point correspond to slightly different ages that fall within the broadly acceptable Bronze Age of the Levant and southern Sinai (Killebrew and Steine, 2014).
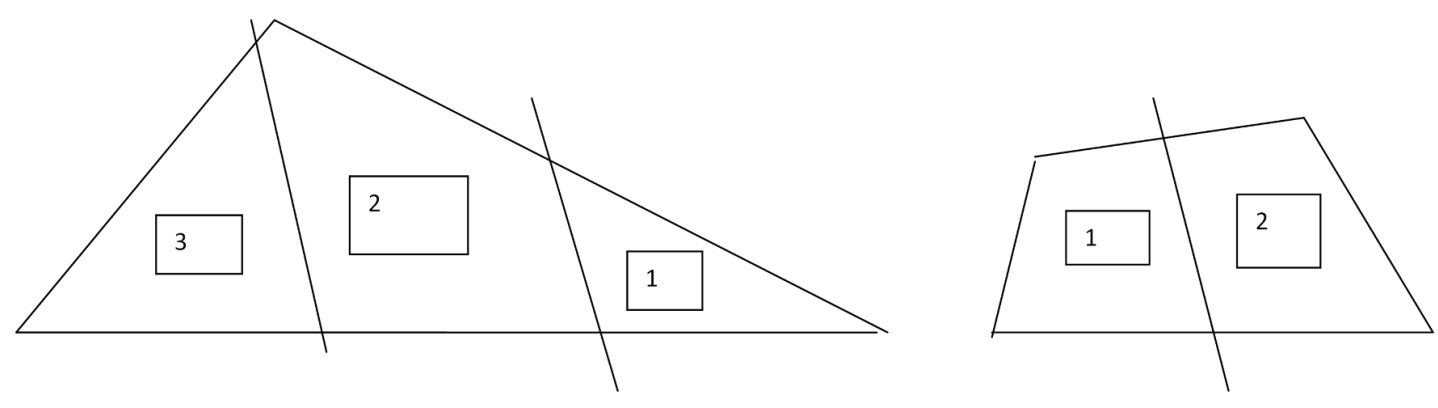

US

LS
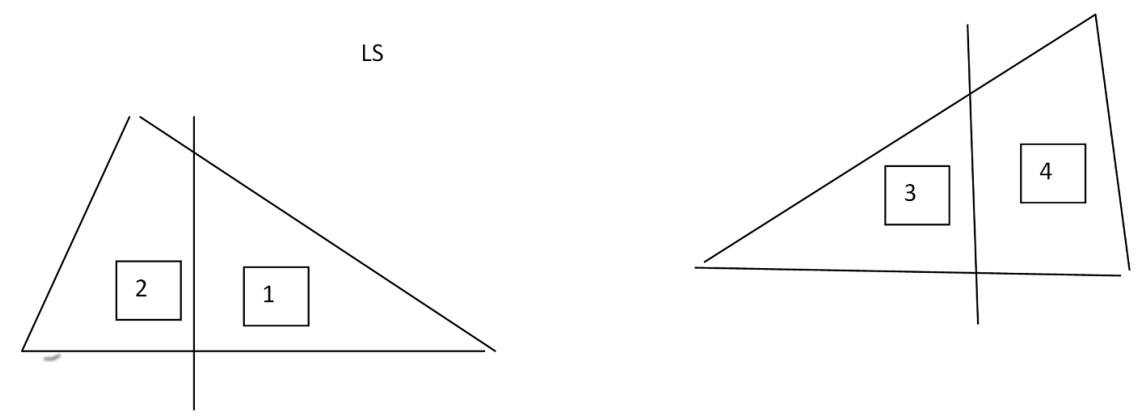

Fig. 6. a) (upper). Sampling three $R O \mathrm{O}$ as aliquot powder at a depth of around $1 \mathrm{~mm}$, from Gebel Gunna, (GG6.1, GG6.2, GG6.3), B1) Ain Khodra, AK8.1.1, AK8.1.2; B2) US upper slab's surface (AK8.2.1, 8.2.2) , LS lower slab's surface (AK8.2.3, AK8.2.4). 


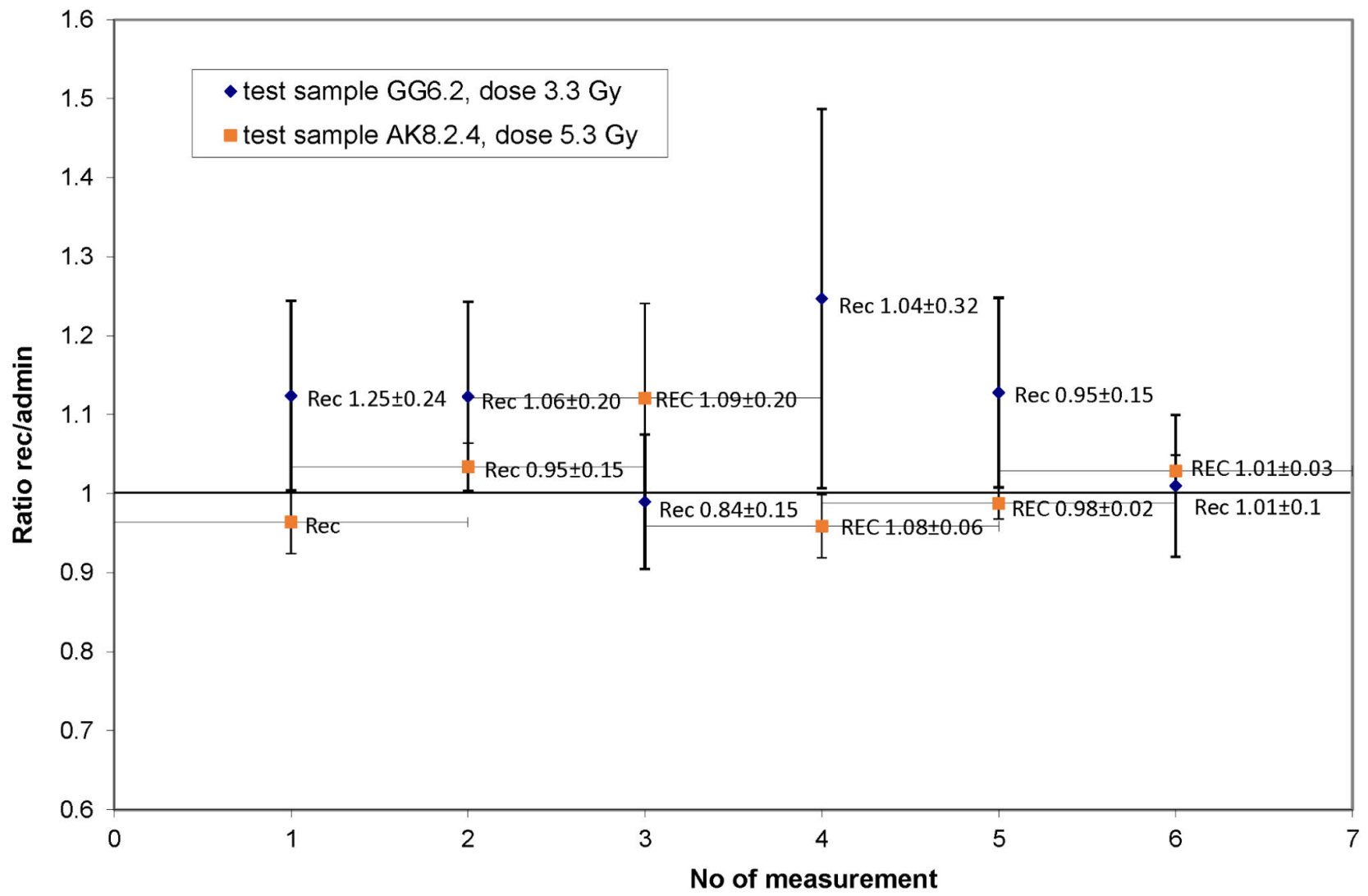

Fig. 7. A multiple dose recovery test (REC numbers) on same 2 aliquots (dose ratio versus the number of measurements): one from sample GG6.2 (diamonds) and one from sample AK.8.2.4 (squares). The numbers shown are the ratios measured, together with their errors.

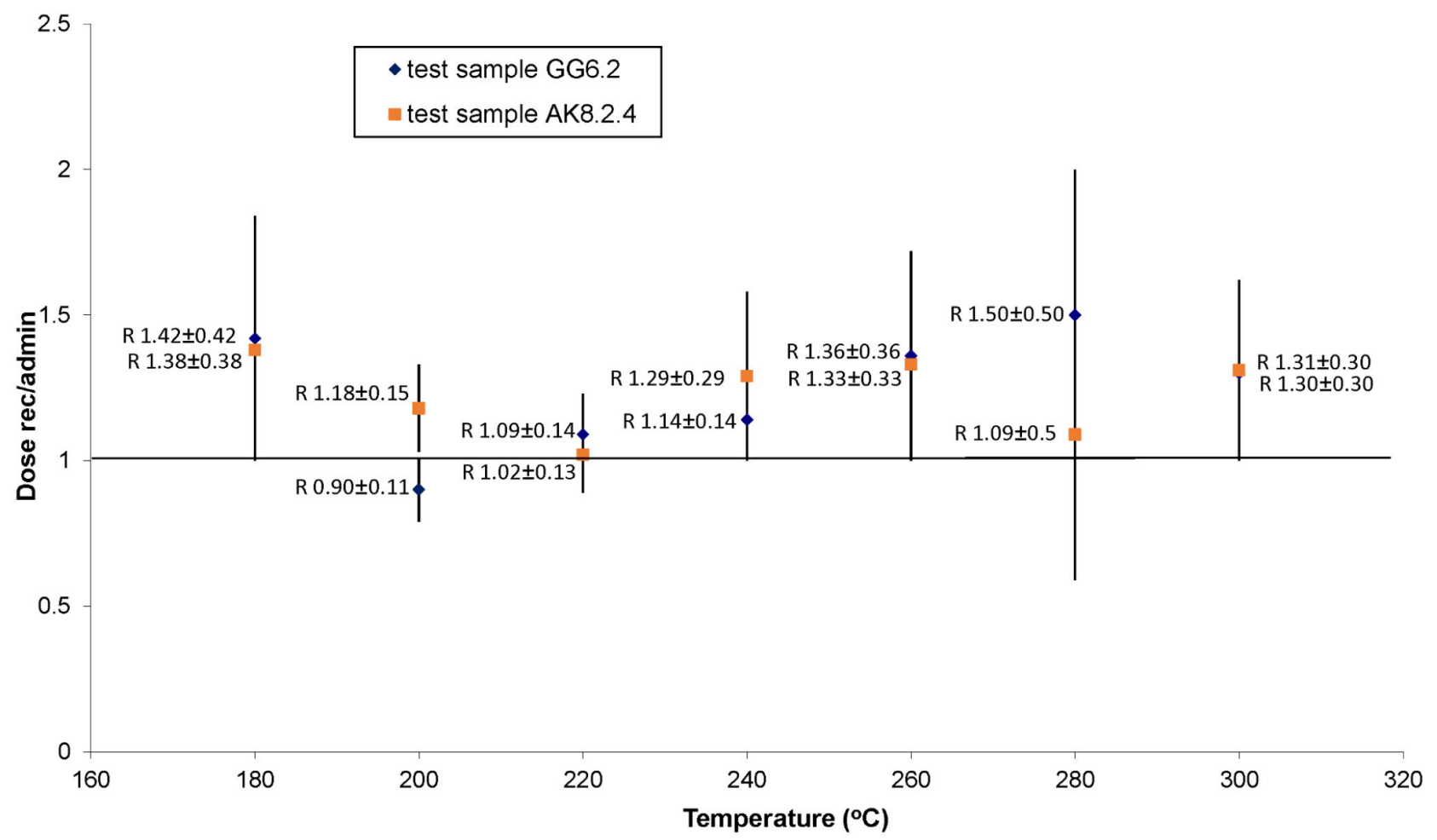

Fig. 8. Pre-heat test using 2 aliquots as in Fig. 6. 
For Gebel Gunna (GG6) the average dose from 3 subsamples provided a highly bracketed dose of $5.13 \pm 0.53$ Gy which corresponds to an age having as mean value the middle $3^{\text {rd }}$ millennium $\mathrm{BC}$ $(2220 \pm 300 \mathrm{BC})$ but spanning throughout that Early Bronze Age millennium.

For the Ain Khodra the two samples (AK8.1, AK8.2) derived from the external wall at a height above the external ground approx. 1 meter, and within a $25 \mathrm{~cm}$ distance between them. The sample 8.1 gave two similar De and a similar age to Gebel Gunna. The adjacent sample 8.2 consisted of two apparently safe contacts; the upper and lower ones from which four smaller, but one, De were deduced.

The age range of two upper surface slab sub-samples (8.2.1 and 8.2.2) from Ain Khodra falls within the $2^{\text {nd }}$ half of $2^{\text {nd }}$ millennium $\mathrm{BC}$ and those lower surface of same slab sub-samples (8.2.3 and 8.2.4) of $2130 \mathrm{BC}$ and $980 \mathrm{BC}$ respectively not averaged due to large difference (see Footnote 7 in Table 2).

Obviously the latter apparent unconformity can be attributed either to later building activities of this part or partial exposure to sunlight. However, the Late Bronze Age presence in Gebel Gunna tombs documented by BarYosef et al. (1986) is also supported by present OSL results.

\section{CONCLUSION}

The dating of two Nawamis tombs from two Nawamis fields in southern Sinai, Gebel Gunna and Ain Khodra, were re-examined, by applying for first time the surface luminescence dating. The standard procedure of sampling for surface luminescence dating of buildings was used, the SAR protocol was employed for ED estimation, and dose rate in mixed radiation field was properly evaluated. Total bleaching is assumed for the upper millimeter surface layer. OSL ages have been derived from nine sub samples of two tombs from Gebel Gunna and Ain Khodra.

Satisfactory criteria tests applied sway opinion that the calculated dates obtained correspond to Levant and southern Sinai archaeological phases of Early Bronze ages with presence of three dates at later Late Bronze period. Archaeological rescue excavation and C14 ages on charcoal from similar tombs as well as detailed typological analysis on plethora of tools indicated an Early Bronze age with some presence at later period.

\section{ACKNOWLEDGEMENTS}

Ioannis Liritzis and Fahad Al-Otaibi thank the Deanship of Scientific Research at King Saud University for funding the execution of work through the research group project No. RGP-VPP-194. IL also thanks Flora Vafea, father Daniel and sister Styliani for their help during one fieldwork season, Archbishop of St Catherine's Monas- tery at Sina Rev.Damianos and the priesthood for their hospitality, Prof.Ashok Sinhgvi for useful comment, and the Supreme Council of Antiquities of Egypt for permission that took place during fieldwork the south of Sinai during June 2006 for the work on Sarabet El-Khadem Temple, made under the supervision of co-author Prof. Mosalam Shaltout in June 2006, Chairman of the mission of Archaeoasrtonomy in the Ancient Egypt. We thank the two anonymous reviewers for constructive comments.

\section{REFERENCES}

Aitken MJ, 1990. Science-Based Dating in Archaeology. Addison Wesley Longman Ltd, London

Aitken MJ, 1985. Thermoluminescence Dating, Academic Press, London.

Bar-Yosef O, Belfer-Cohen A, Goren A, Hershkovitz I, Ilan O, Mienis HK and Sass B, 1986. Nawamis and habitation sites near Gebel Gunna, southern Sinai. Israel Exploration Journal 36: 121-167.

Bar-Yosef O, Belfer-Cohen A, Goren A and Smith P, 1977.. The nawamis near 'Ein Huderah (eastern Sinai). Israel Exploration Journal 27: 65-88.

Bar-Yosef O, Hershkovitz I, Arbel G and Goren A, 1983.. The orientation of nawamis entrances in southern Sinai: expressions of religious belief and seasonality? Tel Aviv 10: 52-60.

Beck $\mathrm{H}$ and de Planque G, 1968. The radiation field in air due to distributed gamma-ray sources in the ground. United States Atomic Energy Commission, Division of Technical Information, HASL195, U.S Dept of Commerce, Springfield, Virginia, 22151.

Botter-Jensen L, Solongo S, Murray AS, Banerjee D and Jungner H, 2000. Using the OSL single-aliquot regenerative-dose protocol with quartz extracted from building materials in retrospective dosimetry. Radiation Measurements 32: 841-845, DOI 10.1016/S1350-4487(99)00278-4.

Greilich S, Glasmacher GA and Wagner GA, 2005. Optical dating of granitic stone surfaces. Archaeometry 47(3): 645-665, 10.1111/j.1475-4754.2005.00224.x.

Greilich S, 2004. Über die Datierung von Gesteinsoberflächen mittels optisch stimulierter Lumineszenz (On the dating of rock surfaces by means of optically stimulated luminescence). Ph.D Dissertation, University of Heidelberg.

Habermann J, Schilles T, Kalchgruber R and Wagner GA, 2000. Steps towards surface dating using luminescence. Radiation Measurements 32: 847-851, DOI 10.1016/S1350-4487(00)00066-4.

Hershkovitz I, Arbel G, Bar-Yosef O and Goren A, 1985.. The relationship between nawamis entrance orientations and sunset direction. Tel Aviv 12: 205-211.

Huntley DJ and Richards MP, 1997. The age of the Diring Yuriakh archaeological site. Ancient TL 15(2-3): 48-49.

Iliopoulos I, Xanthopoulou V and Tsolis-Katagas P, 2011. A petrographic assessment of houseware and storage pithoi in the Early Helladic settlement of Helike, Achaia, Greece. In: D. Katsonopoulou (ed.) Helike IV, Protohelladika: Helike and Aigialeia, The Southern Greek Mainland, pp. 127-142.

Killebrew AE and Steiner M eds, 2014. The Oxford Handbook of the Archaeology of the Levant: c. 8000-332 BCE, Oxford Handbooks in Archaeology, OUP, Oxford, UK, DOI: 10.1093/oxfordhb/9780199212972.001.0001.

Kretz R, 1983. Symbols for rock-forming minerals. American Mineralogist 68: 277-279.

Laskaris N and Liritzis I, 2011. A new mathematical approximation of sunlight attenuation in rocks for surface luminescence dating. Journal of Luminescence 131: 1874-1884, DOI 10.1016/j.jlumin.2011.04.052.

Liritzis I and Galloway RB, 1981. Correlation of variations in the gamma-ray dose-rate in soil with meteorological factors. Archaeometry 23(1): 109-113, DOI 10.1111/j.1475-4754.1981.tb00961.x. 
Liritzis I, 1994. A new dating method by thermoluminescence of carved megalithic stone building. Comptes Rendus Academie des Sciences serie II 319: 603-610.

Liritzis I and Bakopoulos Y, 1997. Functional behaviour of solar bleached thermoluminescence in calcites. Nuclear Instruments and Methods B 132: 87-92, DOI 10.1016/S0168-583X(97)00380-7.

Liritzis I and Galloway RB, 1999. Dating implications from solar bleaching of thermoluminescence of ancient marble. Journal Of Radioanalytical And Nuclear Chemistry 241(2): 361-368, DOI 10.1007/BF02347476.

Liritzis I, Polymeris G and Zacharias N, 2010. Surface luminescence dating of 'Dragon Houses' and Armena Gate at Styra (Euboea, Greece). Mediterranean Archaeology and Archaeometry, Special Issue 10(3): 65-81.

Liritzis I, 2010. Strofilas (Andros Island, Greece): New evidence of Cycladic Final Neolithic dated by novel luminescence and Obsidian Hydration methods. Journal of Archaeological Science 37: 1367-1377, DOI 10.1016/j.jas.2009.12.041

Liritzis I, 2011. Surface dating by luminescence: An Overview. Geochronometria 38(3): 292-302, DOI 10.2478/s13386-011-0032-7.

Liritzis I and Vafiadou A, 2012. Calibration aspects of thick source alpha counter ZnS system. Measurement 45: 1966-1980, DOI 10.1016/j.measurement.2012.04.026.

Liritzis I and Vafiadou A, 2014. Surface luminescence dating of some Egyptian monuments. Journal of Cultural Heritage 16: 134-150, DOI 10.1016/j.culher.2014.05.007.

Liritzis I, Singhvi AK, Feathers JK, Wagner GA, Kadereit A, Zacharias $\mathrm{N}$ and Li S-H, 2013a. Luminescence Dating in Archaeology, Anthropology and Geoarchaeology: An Overview. Springer Briefs in Earth System Sciences, DOI 10.1007/978-3-319-00170-8

Liritzis I, Vafiadou A, Zacharias N, Polymeris GS and Bednarik RG, 2013b. Advances in surface luminescence dating: some new data from three selected Mediterranean sites. Mediterranean Archaeology \& Archaeometry 13(3): 105-115.

Liritzis I, Stamoulis K, Papachristodoulou Ch and Ioannides KG, 2013c. A re-evaluation of radiation dose rate conversion factors. Mediterranean Archaeology \& Archaeometry 13(3): 1-15.
Liritzis I, Aravantinos V, Polymeris GS, Zacharias N, Fappas I, Agiamarniotis G, Sfampa IK, Vafiadou A and Kitis G, 2015. Witnessing prehistoric Delphi by Luminescence dating. Comptes Rendus Palevol 14: 219-232, DOI 10.1016/j.crpv.2014.12.007.

Morgenstein ME, Luo S, Ku TL and Feathers J, 2003. Uranium series and luminescence dating of volcanic lithic artefacts. Archaeometry 45(3): 503-518, DOI 10.1111/1475-4754.00124.

Murray AS and Wintle AG, 2000. Luminescence dating of quartz using an improved single-aliquot regenerative-dose protocol. Radiation Measurements 32: 57-73, DOI 10.1016/S1350-4487(99)00253-X.

Prescott JR and Hutton JT, 1994. Cosmic ray contributions to dose rates for luminescence and ESR dating: Large depths and long-term variations. Radiation Measurements 23: 497-500, DOI 10.1016/13504487(94)90086-8.

Roberts RG, Jacobs Z, Bo Li, Jankowski NR, Cunningham AC, Rosenfeld AB, 2015. Optical dating in archaeology: thirty years in retrospect and grand challenges for the future. Journal of Archaeological Science 56: 41-60, DOI 10.1016/j.jas.2015.02.028.

Sohbati R, 2013. Luminescence, Rock Surfaces. Encyclopedia of Scientific Dating Methods, Springer Science+Business Media Dordrecht 2013, p. 1-7, DOI 10.1007/978-94-007-6326-5_83-4.

Thompson IMG, Botter-Jensen L, Deme S, Pernicka F, Saez-Vergara JC, eds, 1999. EURADOS Working Group 12 "Environmenatl Radiation Monitoring", Technical recommendations on measurements of external environmental gamma radiation field. Radiation Protection 106. European Commission. Luxembourg ISBN 92828-7811-2, $177 \mathrm{p}$.

Vafiadou A, Murray AS and Liritzis I, 2007. Optically Stimulated Luminescence (OSL) dating investigations of rock and underlying soil from three case studies. Journal of Archaeological Science 34: 1659-1669, DOI 10.1016/j.jas.2006.12.004.

Warren SE, 1978. Thermoluminescence dating of pottery - an assessment of the dose-rate from rubidium. Archaeometry 20(1): 71-72, DOI 10.1111/j.1475-4754.1978.tb00215.x.

Wanas HA, 2011. The Lower Paleozoic rock units in Egypt: An overview. Geoscience Frontiers 2(4): 491-507, DOI 10.1016/j.gsf.2011.06.004. 